\title{
VENTRICULAR SEPTAL DEFECT WITH PULMONARY STENOSIS AND AORTIC REGURGITATION
}

\author{
BY \\ D. M. COLlinS, T. EAST, M. P. GODFREY, P. HARRIS, AND S. ORAM \\ From the Cardiological Department, King's College Hospital \\ Received October 17, 1957
}

The combination of ventricular septal defect and pulmonary stenosis with a left-to-right shunt is well recognized (Abrahams and Wood, 1951). These cases differ from the tetralogy of Fallot in that they are acyanotic, there is no dextroposition of the aorta, and the pulmonary blood flow is increased. Ventricular septal defect may also be associated with aortic regurgitation. The earliest reference to this association which we have been able to trace is that of Breccia (1906). Bret (1956) describes cases of Fallot's tetralogy complicated by aortic regurgitation. However, to the best of our knowledge the combination of ventricular septal defect, pulmonary stenosis and aortic regurgitation with a left-to-right shunt has not been described. We wish to report three patients in whom we believe this combination of congenital cardiac defects exists.

\section{CASE Reports}

Case 1. The patient was an unmarried woman, aged 20. A congenital heart lesion had been diagnosed two weeks after birth, and during childhood she was forbidden games. However, her capacity for exercise did not appear to have been limited, and she took part in normal activities out of school hours without distress. At the age of 14 she had suffered from fainting attacks, but these were not related to exertion. She had never been cyanosed. There was no history of rheumatic fever. When first seen in February 1953 there was no disability. The jugular venous pulse was normal. There was prominent arterial pulsation in the neck. The radial pulse was regular and collapsing, the blood pressure being 140/50. The apex beat was in the left mid-clavicular line and of normal character. No right ventricular pulsation could be felt. A faint systolic thrill was palpable in the second left intercostal space, and this was associated with a harsh systolic murmur loudest in the pulmonary area, but audible all over the præcordium. A long blowing diastolic murmur commencing with the second sound could be heard in all areas. The pulmonary second sound was very faint.

The electrocardiogram (Fig. 1) and X-ray appearances were normal. The findings at cardiac catheterization are summarized in Table I. The pressure in the pulmonary artery was normal (25/12), but the right ventricular systolic pressure was slightly increased $(47 \mathrm{~mm} . \mathrm{Hg})$. The withdrawal tracing showed that the change in pressure occurred abruptly at the level of the pulmonary valve, and thus indicated the presence of pulmonary valvular stenosis. The oxygen content of the blood in the pulmonary artery was substantially greater than that in the right atruim and venæ cavæ. The oxygen content of the blood sample taken high in the right ventricle was also increased. At the time these findings were thought to indicate a left-to-right shunt through a patent ductus arteriosus, the increased oxygen content of the blood high in the right ventricle being due either to pulmonary regurgitation or to a co-existing ventricular septal defect. The wide pulse pressure in the systemic arteries appeared to support the diagnosis of a patent ductus.

There was thought to be sufficient evidence to justify thoracotomy with a view to ligation of a patent ductus arteriosus. In March, 1953, operation was performed by Mr. Selwyn Taylor. A coarse systolic thrill was palpable over the base of the pulmonary artery. The suspected ductus arteriosus felt solid; on division it was obvious that the lumen was not patent. 


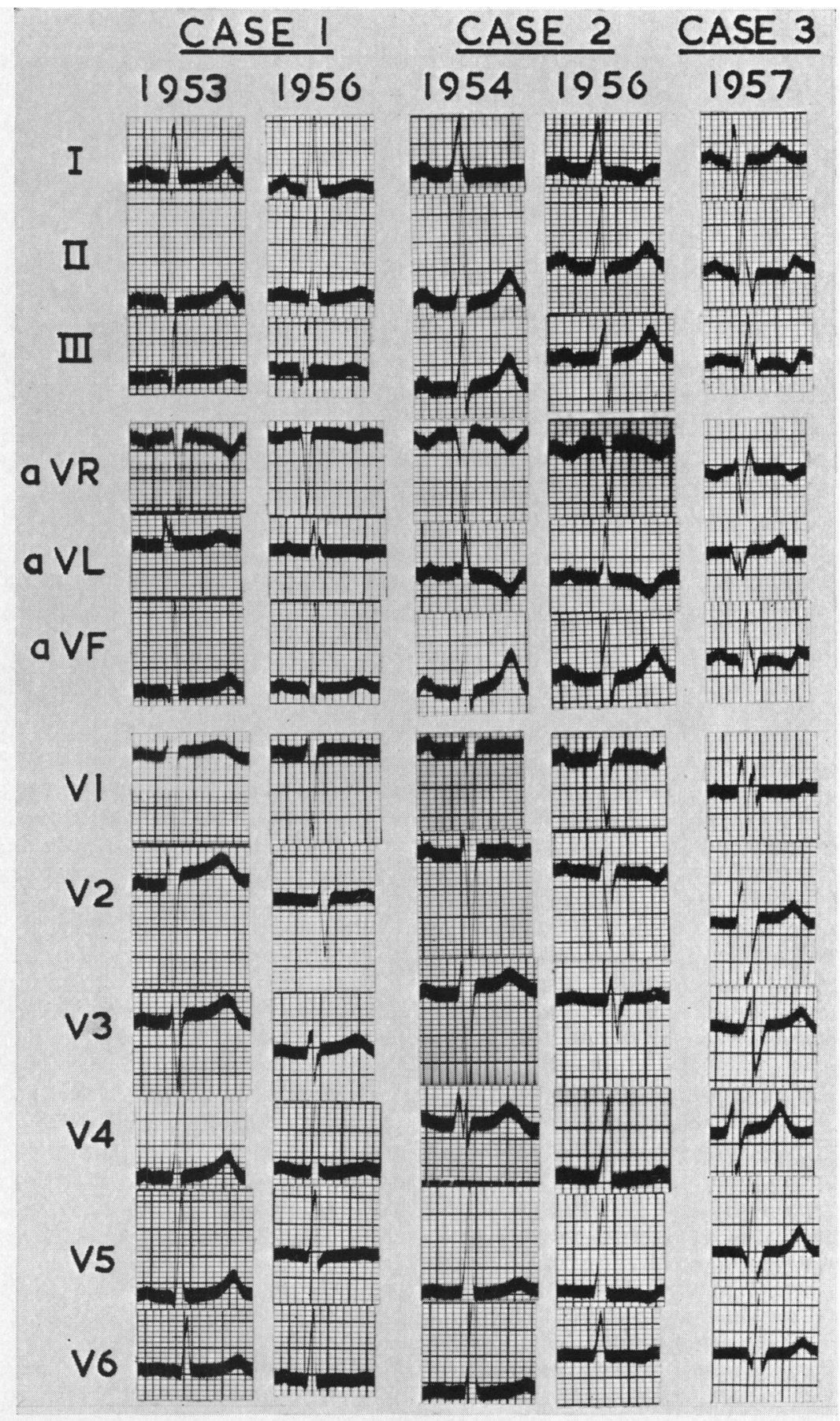

Fig. 1.-Electrocardiograms of the three cases. 
TABLE I

Data obtained at Cardiac Catheterization in Three Patients with V.S.D., Pulmonary Stenosis, and AORTIC Regurgitation

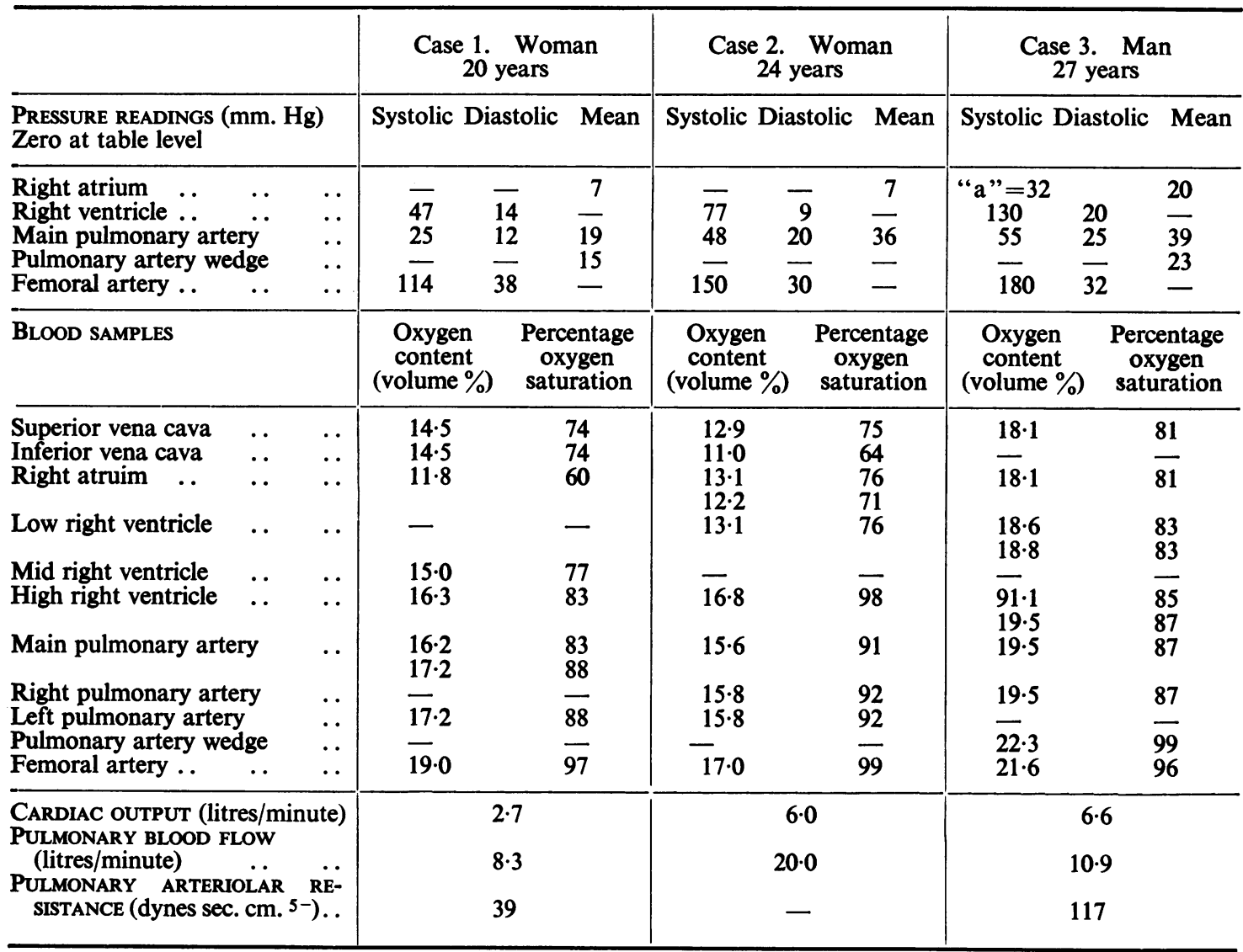

The patient remained well until January, 1956, when she had an attack of bronchitis associated with orthopnœa and on three occasions specks of blood appeared in the sputum. Since then she has become breathless on exertion. The heart is now enlarged and the apex beat is of the left ventricular type. The $X$-ray taken immediately after operation showed the heart to be of normal shape and size (Fig. 2A) but in July, 1956, there was generalized cardiac enlargement, particularly affecting the left ventricle, and an increase in size of the main pulmonary artery and its branches (Fig. 2B). The electrocardiogram now showed flattening of the T waves in leads V4, V5, and V6 (Fig. 1).

Case 2. The patient was a married woman, aged 24. A heart lesion was discovered during infancy and as a child she was made to spend long periods in bed. She thought that she had always been breathless on exertion. At the age of 19 she had an hæmoptysis and tubercle bacilli were found in the sputum. She spent nearly one year in a sanatorium where a right artificial pneumothorax was induced but abandoned after three months. Since that time she had been more short of breath on exertion, and had been subject to recurrent attacks of palpitation, consisting of regular tachycardia, associated with pain spreading across the chest and down the left arm. There was a long history of neurosis, and she had been under the care of a psychiatrist. There was no history of rheumatic fever. When examined in 1954 she was of asthenic build, with a high arched palate and long thin fingers. There was no cyanosis or finger clubbing. The jugular venous pulse was normal. The radial pulse was regular and collapsing, the blood pressure being 125/45. A sustained apex beat was felt external to the mid-clavicular line, and there was prominent right 
ventricular pulsation to the left of the sternum. Systolic and diastolic thrills were palpable to the left of the sternum, and were of greatest intensity in the third and fourth left intercostal spaces. Over the entire præcordium a harsh systolic murmur was heard, loudest in the fourth left space. An equally harsh murmur, starting with the second sound and occupying almost the whole of diastole, was audible in all areas but loudest in the fourth left intercostal space. In the third left intercostal space the murmur sounded roaring and continuous. The aortic second sound was of normal intensity, but the pulmonary second sound was very soft.

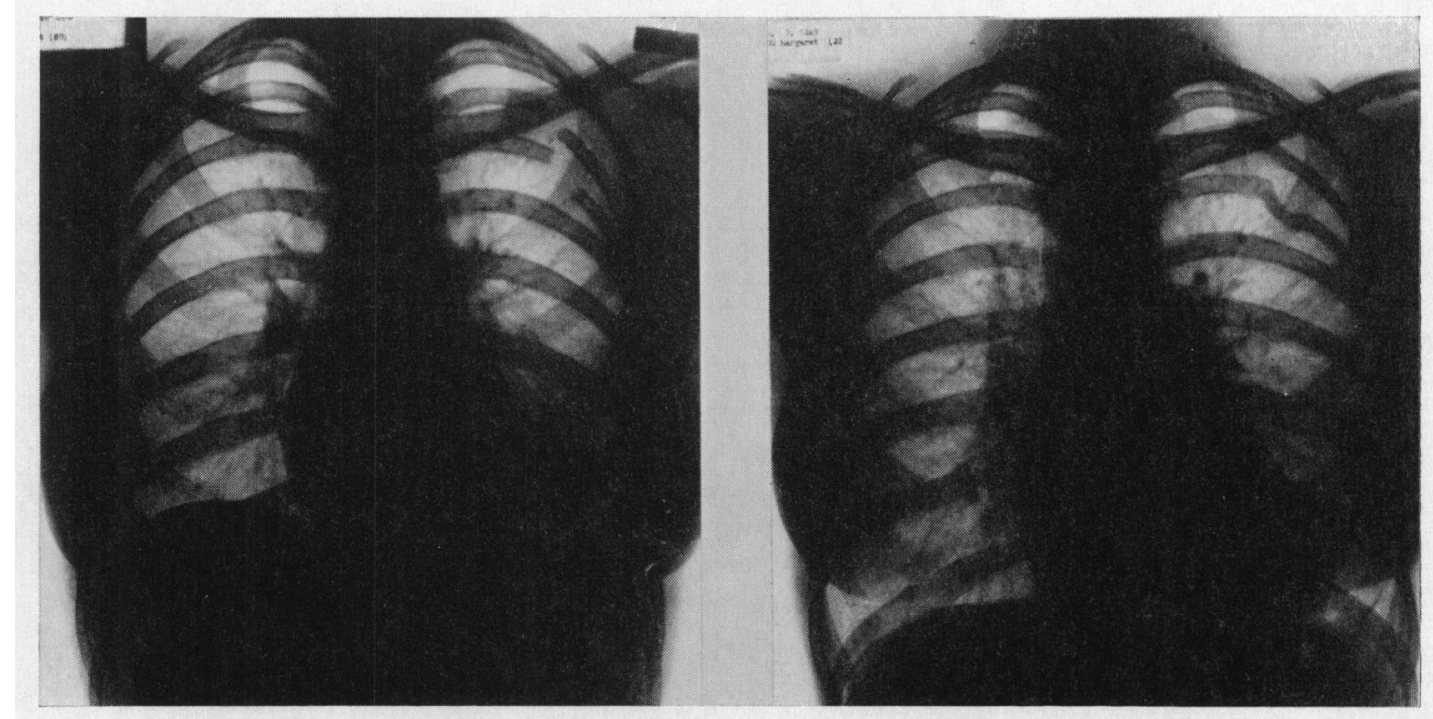

Fig. 2.-X-ray of Case 1. (A) 1953: heart normal. (B) 1956: showing generalized enlargement, especially of the left ventricle and increase in size of the pulmonary artery and its branches.

The electrocardiogram suggested left ventricular hypertrophy. The $T$ waves were inverted in VL, biphasic in I, and of low voltage in V5 and V6 (Fig. 1). X-ray of the chest (Fig. 3A) showed evidence of old tuberculosis in the right upper lobe. There was generalized enlargement of the heart, particularly affecting the left ventricle, and the arterial shadows in the lungs were unduly prominent.

Cardiac catheterization (Table I) showed an increase in the pulmonary artery pressure (48/20), and on withdrawal of the catheter a pulmonary infundibular stenosis was demonstrated, the systolic pressure in the main right ventricle being $77 \mathrm{~mm}$. $\mathrm{Hg}$. The blood in the pulmonary artery, and in one sample from the right ventricle, was excessively oxygenated. The evidence again suggested that the shunt from left to right was due to a communication between the aorta and pulmonary artery, the most likely cause of which would be a patent ductus arteriosus.

Thoracotomy was carried out by Mr. W. P. Cleland on November 2,1954. A patent ductus arteriosus was not present. No abnormality of the aorta could be demonstrated. The aorta and pulmonary artery were separated to within $12 \mathrm{~mm}$. of their origins, and no "window" could be felt between the vessels. At operation the thrill at the base of the heart seemed to be continuous.

Following the operation the patient has gradually become more breathless on exertion. In November, 1956, an attack of bronchitis occurred and subsequently she has been unable to walk for more than 30 yards without dyspnœa; she requires four pillows at night. The heart has increased in size (Fig. 3B) and the electrocardiogram shows evidence of deterioration of the left ventricle (Fig. 1).

Case 3. A married man, aged 27, was found to have a heart lesion at birth. However, he led a normal life, rowed in his school eight, and played all games. There was no history of rheumatic fever. He had never been cyanosed. His father was said to have a heart lesion. For two years he had noticed slight diminution in his athletic ability, but was still able to run for a bus and to climb stairs two at a time. In 


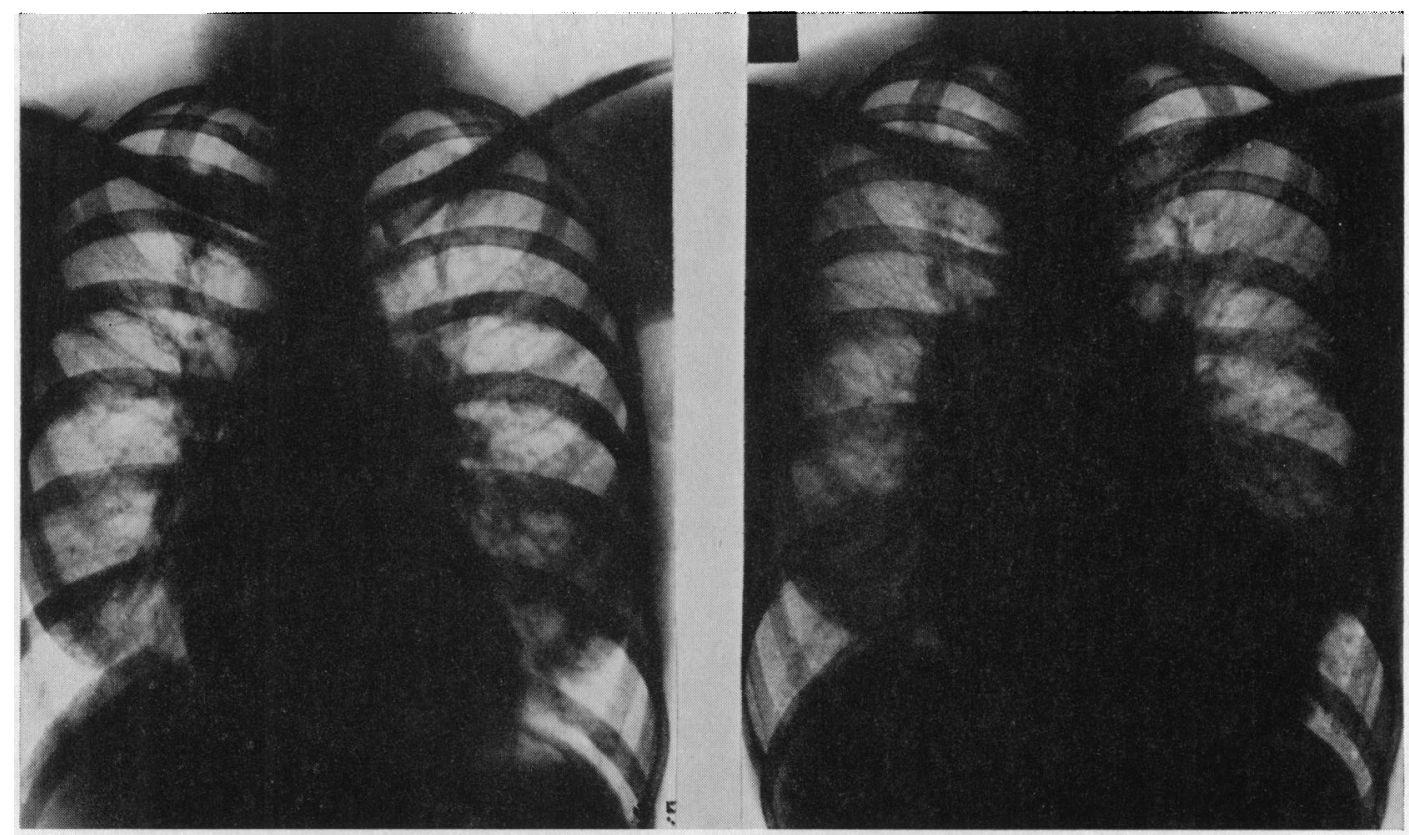

FIG. 3.-X-ray of Case 2. (A) 1954: showing evidence of old tubercle in right upper lobe and generalized cardiac enlargement, particularly of the left ventricle. Prominent arterial shadows in lungs. (B) 1956: showing increase in the size of the heart and the pulmonary artery.

June, 1956, he had a small hæmoptysis following sexual intercourse. Examination in April, 1957 showed a tall, well-built man. A prominent " $a$ " wave could be seen in the venous pulse. The right radial pulse was regular and collapsing, the blood pressure being 180/60. Capillary pulsation was easily discernible. A sustained apex beat was palpable in the seventh left intercostal space in the anterior axillary line, and right ventricular pulsation could be felt to the left of the sternum. A systolic thrill was of greatest intensity in the fourth left intercostal space, and associated with this was a loud harsh systolic murmur heard best where the thrill was maximal but audible over the entire præcordium. A high-pitched, blowing, diastolic murmur commencing with the second sound was heard in all areas. The aortic second sound was loud; the pulmonary second sound could not be heard.

The Wasserman reaction was negative. The electrocardiogram showed right bundle-branch block (Fig. 1). X-ray examination showed enlargement of both right and left ventricles, with increased prominence of the main pulmonary artery and its branches (Fig. 4). In the light of our experience with the two previous cases, a clinical diagnosis of ventricular septal defect with pulmonary stenosis and aortic regurgitation was made.

At cardiac catheterization (Table I) a high " $a$ " wave was recorded in the superior vena cava and right atrium. The pressure in the main pulmonary artery was raised (55/25), and the pulmonary artery wedge pressure was increased $(23 \mathrm{~mm}$. $\mathrm{Hg})$. On withdrawal of the catheter into the right ventricle, a pulmonary infundibular stenosis was demonstrated, the systolic pressure in the main right ventricle being $130 \mathrm{~mm}$. $\mathrm{Hg}$. The increased oxygen content of blood samples from the pulmonary artery and high right ventricle indicated a shunt from left to right.

\section{Discussion}

These three patients showed great similarity clinically, radiologically, and physiologically, and a composite description may be presented. However, it is appreciated that in the absence of confirmation by autopsy, our conception of the malformation is necessarily deductive.

All three patients gave a history of a cardiac murmur in infancy. Two were able to undertake normal activities in childhood and early adult life, but started to experience dyspnœa on exertion in their middle twenties: Case 2 thought that she had always been breathless on exertion, but 


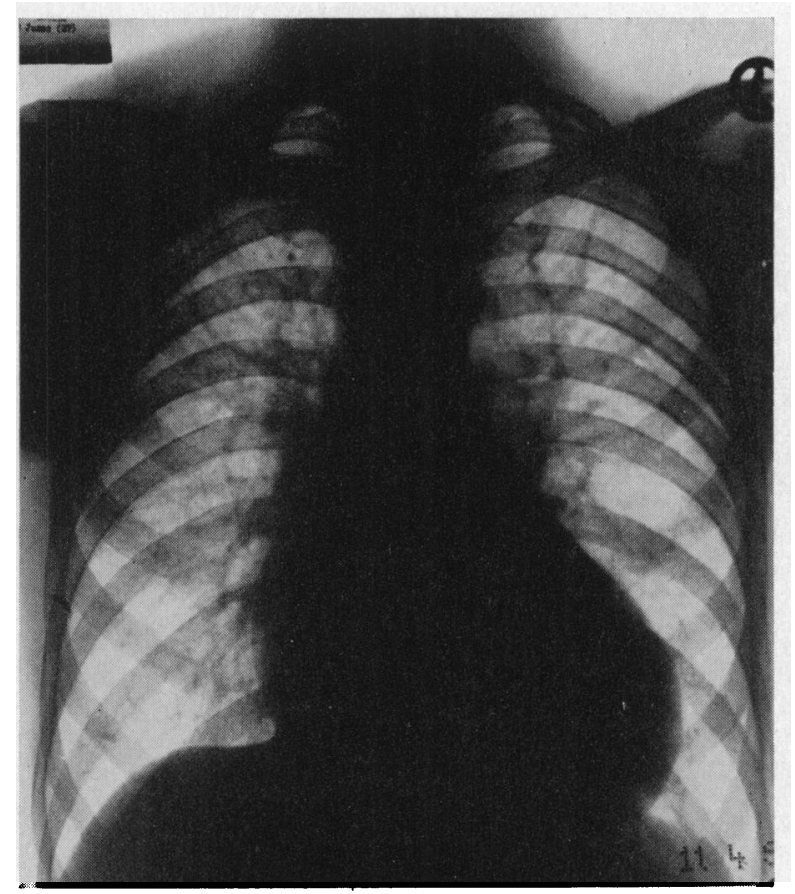

FIG. 4.-X-ray of Case 3. April, 1957: showing enlargement of the right and left ventricles with prominence of the pulmonary artery and its branches.

the breathlessness became much more severe at the age of 26 . The collapsing pulse was a striking feature, and was confirmed by the blood pressure readings. The presence of a dominant " $a$ " wave in the venous pulse, and signs of right ventricular hypertrophy, appear to be related to the severity of the pulmonary stenosis. A sustained apex beat suggesting enlargement of the left ventricle eventually became obvious in all three patients. A systolic thrill could be felt along the left border of the sternum, the exact site of its greatest intensity possibly depending upon the presence of either infundibular or valvular pulmonary stenosis. In one patient a diastolic thrill could also be felt. On auscultation both systolic and early diastolic murmurs were very loud. The intensity and length of these murmurs in Cases 1 and 2 led experienced observers to mistake the "to and fro" quality for the continuous murmur described by Gibson. The pulmonary second sound was very faint or could not be heard.

$\mathrm{X}$-ray examination showed enlargement of both right and left ventricles with increase in the size of the branches of the pulmonary artery. The main pulmonary artery was also prominent in two of the patients. There was no apparent dextroposition of the aorta.

The electrocardiogram was not the same in the three patients. Case 1 and Case 2 eventually showed signs of deterioration of the left ventricle, but in Case 3 the right ventricle appeared to be predominantly affected, which can be explained by the much higher right ventricular pressure in this patient. The resultant pattern, therefore, seems to depend on the relative severity of the pulmonary stenosis and of the overloading of the left ventricle.

Cardiac catheterization demonstrated the presence of pulmonary stenosis, which was situated at the valve in one patient and in the infundibulum in the other two. Blood samples from the pulmonary artery were highly oxygenated and those from the right ventricle showed an unusually wide variation in oxygen content. The findings at operation have ruled out the existence of a patent ductus arteriosus in two cases, and in one of these the possibility of an aortico-pulmonary 
defect was largely eliminated. In the light of these observations the shunt would appear to be due to a ventricular septal defect. Thus the withdrawal of occasional samples with a high oxygen content from the right ventricle is now interpreted as due to an inadequate mixing of the two streams of blood in this chamber, and not to the presence of pulmonary regurgitation.

There was no evidence of a shunt from right to left. Hence, despite the presence of pulmonary stenosis, the pulmonary blood flow exceeded the systemic flow in each case. Two patients showed the unusual combination of pulmonary stenosis with a raised pulmonary arterial pressure. This rise of pressure might be attributed to the effects, direct or indirect, of an increased flow. However, the high wedge pressure in Case 3 suggests that, at least in this patient, a raised left atrial pressure played some part in causing the pulmonary hypertension. Such a raised atrial pressure would imply a degree of failure of the left ventricle which is overloaded both by the aortic regurgitation and by the ventricular septal defect.

Since the first two patients were mistakenly thought to have a patent ductus arteriosus, it is relevant to consider the factors that gave rise to this erroneous diagnosis. The main difficulty was the murmur. This was in no case the typical murmur of a patent ductus, yet the intensity and duration of both systolic and diastolic elements were such as to suggest a continuous quality. The other cause of error was the collapsing pulse, which made a patent ductus arteriosus appear to be the more likely cause of the left-to-right shunt than a ventricular septal defect. Now that the presence of a patent ductus has been excluded, the collapsing pulse and the diastolic element of the murmur can with reasonable certainty be ascribed to aortic regurgitation.

It is pertinent to note that Soulié et al. (1949) experienced similar difficulties in distinguishing ventricular septal defect with aortic regurgitation from patent ductus arteriosus, as a result of misinterpreting the collapsing pulse, the murmur, and the findings at catheterization.

\section{SUMMARY}

A description is given of three patients who appear to have ventricular septal defect with a leftto-right shunt, combined with pulmonary stenosis and aortic regurgitation. In two of these patients the shunt was erroneously thought to be through a patent ductus arteriosus, but this was disproved at operation. In the third patient the clinical and physiological features appeared to be sufficiently characteristic to establish the diagnosis without thoracotomy.

\section{REFERENCES}

Abrahams, D. G., and Wood, P. (1951). Brit. Heart. J., 13, 519.

Breccia, G. (1906). Gazetta degli Ospedali e delle Cliniche, 27, 625.

Bret, J. (1956). Arch. Mal. Ceeur., 49, 1053.

Soulié, P., Routier, D., and Bernal, P. (1949). Arch. Mal. Caeur., 42, 765. 